\title{
PENERAPAN IoT (Internet of Thing) TERHADAP RANCANG BANGUN SANGKAR BURUNG PINTAR UNTUK BURUNG TERIEP
}

\author{
Firmanda Revivaldy Mucthar, Suryo Adi Wibowo, F.X Ariwibisono \\ Program Studi Teknik Informatika S1, Fakultas Teknologi Industri \\ Institut Teknologi Nasional Malang, Jalan Raya Karanglo km 2 Malang, Indonesia \\ revivaldy10.fr@gmail.com
}

\begin{abstract}
ABSTRAK
Pada zaman sekarang banyak orang yang gemar untuk beternak burung mulai dari peternakan kecil hingga peternakan berskala besar. Permasalahan yang sering dihadapi oleh peternak burung berskala besar adalah proses untuk merawat burung dan keterlambatan untuk memberi makan dan minum burung. Dengan adanya permasalahan ini maka peneliti merancang sistem yang dimana sangkar burung dapat bekerja secara otomatis dan dapat mengirim data dari setiap sensor ke website. Sistem yang dirancang berupa pemberian pakan dan minum secara otomatis, monitoring suhu sangkar, membuat sistem keamanan yang dimana untuk dapat membuka pintu sangkar harus melakukan pengecekan sidik jari, dan melatih suara burung dengan cara memutar suara pemacing dengan bantuan speaker. Dari hasil pengujian alat pada sistem sangkar burung pintar didapatkan presentase kesalahan pada sensor ultrasonic sebesar 2.84\%, sensor water level sebesar $6.63 \%$, serta sensor dht $112.4 \%$. Rtc dapat mengkontroling setiap alat dengan mengatur waktu untuk alat bekerja. Untuk alat pada tempat pakan dan minum burung akan aktif pada pukul 12.00 siang dan menampilkan data website, suhu sangkar akan terupdate di website setiap 30 menit sekali, dan jika suhu sangkar $34 \mathrm{C}$ maka fan akan aktif dan off jika suhu turun dari 34 C. Dfplayer mini akan aktif setiap 1 jam sekali.
\end{abstract}

Kata kunci: Microkontroller Arduino Mega 2560, RTC (Real Time Clock), Module DFPlayer Mini, ESP826601 .

\section{PENDAHULUAN}

Burung Teriep merupakan burung khas kalimatan yang masih berkeluarga dengan burung Lovebird yang memiliki bulu yang indah dan suara yang bagus. Penggemar dan peternak burung teriep atau lovebird di Indonesia mulai mengembangkan metode pemeliharaan dari cara tradisional menjadi intensif. Pola pemeliharaan secara intensif diterapkan dengan tujuan untuk mendapatkan kualitas burung teriep unggul. Keunggulan burung teriep terdapat pada kualitas suara dan warna bulu, sehingga berbagai perlombaan burung teriep mengutamakan kualitas suara dan keindahan bulu sebagai parameter utama dalam menentukan pemenang.

Pemeliharaan secara intensif memerlukan perlakuan khusus terhadap pemberian makanan dan minuman. Pemberian makanan dan minuman memerlukan waktu dan tenaga bagi para peternak. Apabila jumlah ternak burung teriep dalam skala besar menyebabkan biaya pemeliharaan juga meningkat dan waktu yang semakin lama. Jika peternak burung sedang sibuk maka akan susah melakukan perawatan terhadap burung. Dengan permasalahan ini maka penulis membuat sistem yang dapat membantu peterknak untuk merawat burung.

Dalam penelitian ini, membuat sistem sangkar burung dengan sistem otomatis dalam pemberian makanan, minuman, monitoring suhu sangkar, membuat suara pemancing untuk melatih burung ini supaya sering berkicau dan membuat sistem keamanan sangkar dengan mendeteksi sidik jari pemilik untuk membuka pintu sangkar. Sebuah sangkar dengan RTC (Real Time Clock) yang digunakan untuk mengatur jam pemberian pakan, minum dan mengaktifkan speaker untuk membunyikan suara burung teriep. Sensor infrared digunakan untuk mendeteksi pakan yang ada di tempat pakan burung dan sensor ultrasonic digunakan untuk mendeteksi pakan pada penampungan. Sensor water level digunakan untuk mendeteksi banyaknya air pada wadah air minum burung jika air minum habis maka sensor water level akan mengirimkan data ke Arduino untuk mengaktifkan pump dan menyalurkan air ke wadah air minum. Sensor DHT11 digunakan untuk memonitoring suhu pada kandang burung, jika kandang burung berada di suhu $35 \mathrm{C}$ maka Arduino akan mengaktifkan fan untuk mendinginkan kandang. Untuk kemanan kandang menggunakan sensor fingerprint dan solenoid door lock yang dimana jika sidik jari yang terdeteksi terdaftar maka solenoid door lock akan aktif. ESP8266 01 digunakan mengirimkan data dari sensor ke website. Serta menambahkan fitur untuk malatih suara burung dengan menggunakan module MP3 DFPlayer Mini yang disambungkan ke speaker untuk dapat membunyikan suara.

\subsection{Rumusan Masalah}

Setelah dipaparkan pada latar belakang, maka dapat disimpulkan dengan masalah sebagai berikut:

1. Bagaimana merancang dan membangun sistem pemberi makan, minum secara otomatis, keamanan sangkar burung, monitoring suhu sangkar burung dan melatih suara burung agar dapat aktif berkicau? 
2. Bagaimana merancang dan membangun sistem sangkar burung pintar untuk burung teriep yang dapat di monitoring dari website?

3. Bagaimana melakukan pengujian pada sistem sangkar burung pintar dengan waktu yang telah ditentukan?

\subsection{Batasan Masalah}

Agar dalam penulisan penelitian yang dibuat tidak meluas, maka penelitian ini memiliki batasan masalah sebagai berikut:

1. Dataset yang digunakan pada pengembangan aplikasi adalah hasil pengambilan data langsung dari sensor.

2. Platform yang digunakan untuk melakukan monitoring menggunakan website.

3. Website monitoring menggunakan server local untuk menghindari adanya gangguan jaringan dan keterlambatan eksekusi perintah.

4. Project skripsi diarahkan pada kandang burung yang berkapasitas jumlah besar misal 100 burung 1 kandang, untuk menyeimbangkan biaya operasional dan hasil penjualan burung.

\subsection{Tujuan}

Adapun tujuan yang diharapkan dari pelaksanaan penelitian ini sebagai berikut:

1. Untuk merancang dan membangun sistem sangkar burung pintar dengan menerapkan sistem IoT.

2. Untuk mengembangkan sistem sangkar burung pintar dengan monitoring lewat website dengan bantuan modul ESP8266-01.

3. Untuk mengembangkan sistem sangkar burung yang dapat bekerja secara otomatis dengan waktu yang telah ditentukan dalam skala peternakan besar.

\section{TINJAUAN PUSTAKA}

\subsection{Penelitian Terdahulu}

Ditahun 2018 Shoenandia Agil Sahrian dan Ir. Subekti Yuliananda, M.T. Mengambangkan sistem pemberi makan dan minum, karena dalam memelihara burung cinta, memberi pakan dan minum yang teratur sudah menjadi suatu keharusan yang harus dilakukan agar burung cinta tidak kekurangan nutrisi yang dapat berakibat kematian pada burung cinta peliharaan. Adapun kendala yang umum terjadi pada pemeliharaan burung cinta adalah ketidakteraturan dalam waktu pemberian pakan dan minum pada burung cinta. Akibatnya tidak jarang burung cinta menjadi kurang pakan dan minum bahkan sampai berakibat kematian pada peliharaan tersebut. Dengan perkembangan dunia elektronika yang semakin hari semakin canggih, memungkinkan untuk membuat suatu sistem yang dapat meminimalkan permasalahan diatas (khususnya pada pemberian pakan dan minum burung cinta). Dengan pempertimbangkan hal tersebut, muncullah ide tugas akhir tentang Rancang Bangun Alat Pemberi Pakan-Minum Burung Cinta
(Lovebird) Berbasis Mikrokontroler Atmega16. pembuatan alat ini dapat membantu para pemelihara dan peternak burung cinta untuk memberikan pakan dan minum ke burung cinta. Selain itu, para pemelihara burung cinta dapat menjalankan kesibukannya tanpa khawatir burung cinta mereka kekurangan pakan dan minum karena telah menggunakan alat ini. [1]

Pada tahun 2018 Bagas Pratama Putra membuat suatu sistem yang diharapkan dapat mengurangi resiko permasalahan dalam ketersediaan pakan, air, dan suhu ideal untuk mempermudah para peternak burung. Pemberian pakan memanfaatkan sensor ultrasonik sebagai pemicu untuk menjalankan motor servo untuk membuka penutup penampung pakan. Pengisian air memanfaatkan pompa air sebagai penyedot air dari tangki penampung air menuju wadah air yang ada di kandang dengan menggunakan sensor water level yang terletak pada wadah air di kandang sebagai indikator ketersediaan air dan pemicu pompa air untuk bekerja. Mengontrol suhu ruangan dengan memanfaatkan sensor dht11 sebagai pemicu untuk mengaktifkan kipas atau pemanas apabila suhu di dalam ruangan terlalu panas atau dingin. [2]

Pada tahun 2019 Arief Rahman Wibowo membuat sangkar burung otomatis yang dapat memberikan makan serta minum secara otomatis. Selain itu penulis juga membuat sangkar burung tersebut dapat membuang kotoran burung secara otomatis pula. Pada tugas akhir ini penulis menggunakan Arduino Uno sebagai pusat kontrol. Sedangkan input adalah sensor water level dan sensor infrered serta tombol manual. Untuk output adalah solenoid door lock, solenoid valve, kipas, LCD dan Conveyor. Berdasarkan Hasil pengujian didapatkan bahwa pada Mode manual dan otomatis memiliki tingkat keberhasilan $100 \%$ dan error 0\%, karena input dan output dapat berjalan sesuai apa yang diharapkan, meliputi pengujian sensor, pengujian waktu, dan pengujian manual. [3]

Sedangkan pada tahun 2020 Andry Halomoan Ompusunggu, Joseph Dedy Irawan dan Suryo Adi Wibowo mengembangkan alat MIDI Drum Controller menggunakan Sensor Piezoelectric dan menguji kelayakan untuk bermain Drum itu sendiri. Alat yang dikembangkan ini sebagai alternatif bagi pemula yang ingin bermain Drum dan penggunaan membuat musik terutama pada aspek digital. Piezoelectric adalah sebuah sensor yang dapat mendeteksi adanya getaran sehingga dapat membuat Dinamika pada saat memainkan Drum. [4]

\subsection{Mikrokotroller Arduino Mega 2560}

Board Arduino Mega 2560 adalah sebuah Board Arduino yang menggunakan ic Mikrokontroler ATmega 2560.Board ini memiliki Pin I/O yang relatif banyak, 54 digital Input / Output, 15 buah di antaranya dapat di gunakan sebagai output PWM, 16 buah analog Input, 4 UART. Arduino Mega 2560 di lengkapi kristal 16. Mhz Untuk penggunaan, relatif sederhana tinggal 
menghubungkan power dari USB ke PC / Laptop atau melalui Jack DC pakai adaptor 7-12 V DC. [8]

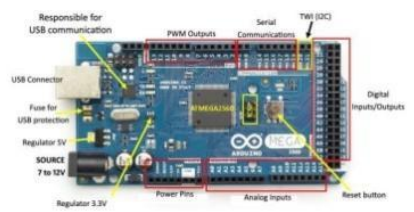

Gambar 1 Arduino Mega 2560

\subsection{RTC (Real Time Clock) DS3231}

Komponen Realtime clock adalah komponen IC penghitung yang dapat difungsikan sebagai sumber data waktu baik berupa data jam, hari, bulan maupun tahun. Komponen DS1307 berupa IC yang perlu dilengkapi dengan komponen pendukung lainnya seperti crystal sebagai sumber clock dan Battery External 3,6 Volt sebagai sumber energy cadangan agar fungsi penghitung tidak berhenti. [2]

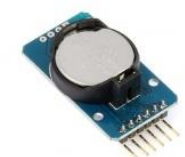

Gambar 2 RTC DS3231

\subsection{Modul ESP8266-01}

ESP8266 merupakan modul wifi yang berfungsi sebagai perangkat tambahan mikrokontroler seperti Arduino agar dapat terhubung langsung dengan wifi dan membuat koneksi TCP/IP. Modul ini membutuhkan daya sekitar 3.3v dengan memiliki tiga mode wifi yaitu Station, Access Point dan Both (Keduanya). Modul ini juga dilengkapi dengan prosesor, memori dan GPIO dimana jumlah pin bergantung dengan jenis ESP8266 yang kita gunakan. Sehingga modul ini bisa berdiri sendiri tanpa menggunakan mikrokontroler apapun karena sudah memiliki perlengkapan layaknya mikrokontroler. [2]

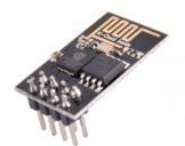

\section{Gambar 3 Modul ESP8266-01}

\subsection{Modul Mp3 DFPlayer Mini}

DFPlayer Mini merupakan module pemutar file audio / module sound player music dengan support format audio seperti file .mp3 yang sudah umum dikenal oleh khalayak umum. Bentuk fisik dari DFPlayer mini ini berbentuk persegi dengan ukuran 20 x $20 \mathrm{~mm}$ yang dimana memiliki 16 kaki pin. Output pada module mp3 mini ini dapat langsung dihubungkan dengan speaker mini ataupun amplifier sebagai pengeras suaranya. [9]

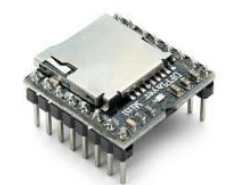

Gambar 4 Modul Mp3 DFPlayer Mini

\subsection{Sensor Sidik Jari AS608}

Fingerprint adalah sebuah alat elektronik yang menerapkan sensor scanning untuk mengetahui sidik jari seseorang guna keperluan verifikasi identitas. Sensor Fingerprint seperti ini digunakan pada beberapa peralatan elektronik seperti smartphone, pintu masuk, alat absensi karyawan dan berbagai macam peralatan elektronik yang membutuhkan tingkat keamanan yang tinggi, dan hanya bisa di akses oleh orang - orang tertentu saja. Sebelum sensor Fingerprint ditemukan, dahulu sebuah data di amankan dengan menggunakan password atau ID, ada juga yang menggunakan pola guna mengamankan suatu data. [7]

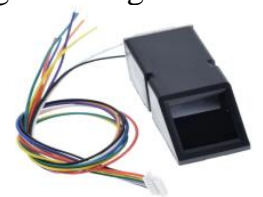

Gambar 5 Sensor Sidik Jari AS608

\subsection{Sensor Infrared IR}

Cahaya infra merah merupakan cahaya yang tidak tampak. Jika dilihat dengan spektroskop cahaya maka radiasi cahaya infra merah akan terlihat pada spektrum elektromagnet dengan panjang gelombang di atas panjang gelombang cahaya merah. [5]

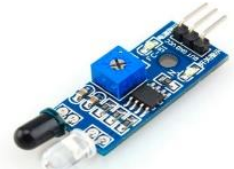

Gambar 6 Sensor Infrared IR

\subsection{Sensor Ultrasonik HC-SR04}

Gelombang ultrasonik merupakan gelombang yang umum digunakan untuk radar untuk mendeteksi keberadaan suatu benda dengan memperkirakan jarak antara sensor dan benda tersebut. sensor jarak yang umum digunakan dalam penggunaan untuk mendeteksi jarak yaitu sensor ultrasonik. pengertian sensor ultrasonik adalah sebuah sensor yang berfungsi untuk mengubah besaran fisis (bunyi) menjadi besaran listrik dan sebaliknya. [3]

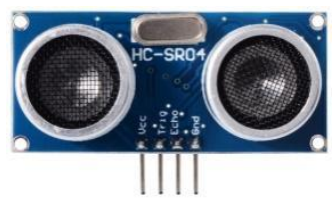

Gambar 7 Sensor Ultrasonik HC-SR04 


\subsection{Sensor Water Level}

Pengertian Water Level sendiri adalah seperangkat alat yang digunakan untuk mengukur ketinggian air di tempat yang berbeda agar mendapatkan data perbandingan. Water level yang paling sederhana adalah sepasang pipa yang saling terhubung di bagian bawah. Water level sederhana akan mengukur ketinggian air melalui tinggi air di kedua pipa apakah sama atau tidak. Hasil pengukuran dari water level lebih rendah dari menggunakan laser tetapi water level mempunyai akurasi yang tinggi dalam pengukuran jarak jauh. Untuk menghindari kesalahan pengukuran dalam penggunaan water level, suhu pada air haruslah sama. [5]

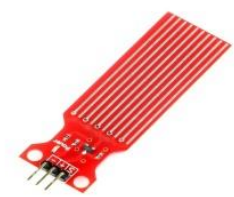

Gambar 8 Sensor Water Level

\subsection{Sensor DHT11}

Sensor DHT11 merupakan serangkaian komponen senor dan IC kontroller yang dikemas dalam satu paket. Sensor ini ada yang memiliki 4 pin ada pula yang 3 pin. Tapi tidak menjadi masalah karena dalam penerapannya tiak ada perbedaan. Didalam bodi sensor yang berwarna biru atau putih terdapat sebuah Resistor dengan tipe NTC (Negative Temperature Coefficient). [7]

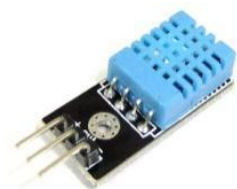

Gambar 9 Sensor DHT11

\subsection{Solenoid Door Lock}

Solenoid ini berfungsi sebagai aktuator. Prinsip dari solenoid sendiri akan bekerja sebagai pengunci dan akan aktif ketika diberikan tegangan. Didalam solenoid terdapat kawat yang melingkar pada inti besi. Ketika arus listrik mengalir melalui kawat ini, maka terjadi medan magnet untuk menghasilkan energi yang akan menarik inti besi ke dalam. [6]

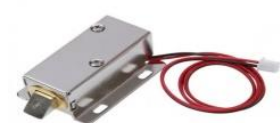

\section{Gambar 10 Solenoid Door Lock}

\subsection{Water Pump Mini}

Water Pump merupakan jenis pompa yang menggunakan motor dc dan tegangan searah sebagai sumber tenaganya. Dengan memberikan beda tegangan pada kedua terminal tersebut, motor akan berputar pada satu arah, dan bila polaritas dari tegangan tersebut dibalik maka arah putaran motor akan terbalik pula. Polaritas dari tegangan yang diberikan pada dua terminal menentukan arah putaran motor, sedangkan besar dari beda tegangan pada kedua terminal menentukan kecepatan motor. [5]

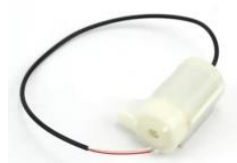

Gambar 11 Water Pump Mini

\subsection{Motor Sevo}

Motor servo adalah komponen elektronika yang berupa motor yang memiliki sistem feedback guna memberikan informasi posisi putaran motor aktual yang diteruskan pada rangkaian kontrol mikrokontroler. Pada dasarnya motor servo banyak digunakan sebagai aktuator yang membutuhkan posisi putaran motor yang presisi. Apabila pada motor DC biasa hanya dapat dikendalikan kecepatannya serta arah putaran, lain halnya pada motor servo yaitu penambahan besaran parameter yang dapat dikendalikan berdasarkan sudut/derajat. [6]

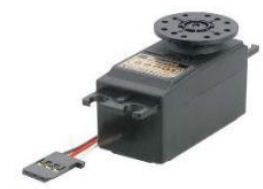

Gambar 12 Motor Servo

\subsection{Fan}

Kipas angin ( $\mathrm{fan}$ ) adalah perangkat mekanis yang digunakan untuk membuat aliran gas kontinu seperti udara. Dalam setiap system pendingin, yang menggunakan gas sebagai penghantar, kipas angina adalah unit wajib yang menciptakan aliran udara dalam system. System ini dapat dilihat dalam kipas angina sederhana yang digunakan dirumah tangga atau kipas pendingin eksternal untuk mesin pembakaran internal. Ketika membutuhkan tekanan yang lebih tinggi diperlukan blower yang digunakan untuk pengganti kipas angin. [7]

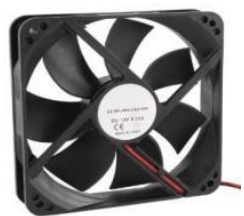

Gambar 13 Fan/Kipas Angin

\subsection{Speaker}

Speaker adalah perangkat keras output yang berfungsi mengeluarkan hasil pemrosesan oleh CPU berupa audio/suara. Speaker juga bisa di sebut alat bantu untuk keluaran suara yang dihasilkan oleh perangkat musik seperti MP3 Player, DVD Player dan lain sebagainya. [9] 


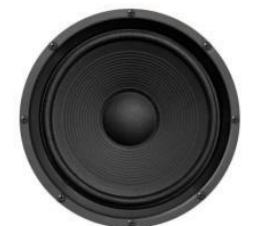

Gambar 14 Speaker

\subsection{Relay}

Relay adalah suatu peranti yang bekerja berdasarkan elektromagnetik untuk menggerakan sejumlah kontaktor yang tersusun atau sebuah saklar elektronis yang dapat dikendalikan dari rangkaian elektronik lainnya dengan memanfaatkan tenaga listrik sebagai sumber energinya. Kontaktor akan tertutup (menyala) atau terbuka (mati) karena efek induksi magnet yang dihasilkan kumparan (induktor) ketika dialiri arus listrik. Berbeda dengan saklar, pergerakan kontaktor (on atau off) dilakukan manual tanpa perlu arus listrik. Relay yang paling sederhana ialah relay elektromekanis yang memberikan pergerakan mekanis saat mendapatkan energi listrik. Secara sederhana relay elektromekanis ini didefinisikan sebagai Saklar yang digerakkan secara mekanis oleh daya atau energi listrik. [10]

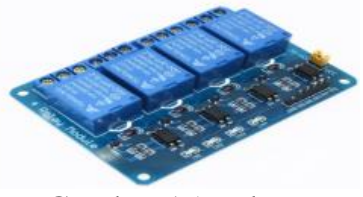

Gambar 15 Relay

\subsection{Power Supply 12V}

Power Supply adalah perangkat keras yang berfungsi untuk menyuplai tegangan langsung kekomponen dalam casing yang membutuhkan tegangan, misalnya motherboard, hardisk, kipas, dll. Input power supply berupa arus bolak-balik (AC) sehingga power supply harus mengubah tegangan $\mathrm{AC}$ menjadi DC (arus searah), karena hardware komputer hanya dapat beroperasi dengan arus DC. Power supplyberupa kotak yang umumnya diletakan dibagian belakang atas casing. Power Supply dapat dilihat pada Gambar dibawah ini. [3]

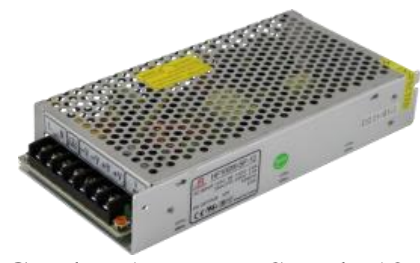

Gambar 16 Power Supply 12V

\subsection{Buzzer}

Buzzer merupakan komponen elektronika yang cara kerjanya mengubah sinyal listrik menjadi getaran suara/bunyi. [8]

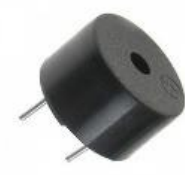

Gambar 17 Buzzer

\section{METODE PENELITIAN}

3.1. Analisis Kebutuhan Fungsional

Adapun beberapa kebutuhan fungsional dalam sistem rancangan sangkar burung pintar sebagai berikut:

Tabel 1 Kebutuhan Fungsional

\begin{tabular}{|l|l|c|}
\hline No. & \multicolumn{1}{|c|}{ Hardware } & \multicolumn{1}{|c|}{ Software } \\
\hline 1. & Arduino Mega 2560 & $\begin{array}{l}\text { Arduino IDE } \\
\text { Sublim Text }\end{array}$ \\
\hline 2. & Modul ESP8266 & Web browser \\
\hline 3. & Sensor Ultrasonik & XAMPP \\
\hline 4. & Sensor Infrared IR & - \\
\hline 5. & Sensor DHT11 & - \\
\hline 6. & Sensor Water Level & - \\
\hline 7. & Sensor Fingerprint & - \\
\hline 8. & Motor Servo & - \\
\hline 9. & Solenoid Door Lock & - \\
\hline 10. & RTC & - \\
\hline 11. & Water pump mini & - \\
\hline 12. & Modul DFPlayer Mini & - \\
\hline 13. & Fan & - \\
\hline 14. & Relay & - \\
\hline 15. & Power Supply 12V & - \\
\hline 16. & Speaker & \\
\hline
\end{tabular}

\subsection{Blok Diagram Sistem}

Blok diagram adalah diagram dari sebuah sistem, di mana bagian menjelaskan monitoring pada rancang bangun kandang burung pintar yang menggunakan modul wifi esp8266 yang dikontrol menggunakan Arduino. Pada saat inisialisasi alat telah selesai maka rtc akan aktif dan mengirimkan perintah kesemua alat untuk menjalakan perintah dari masing - masing. Setelah semua alat selesai melaksanakan tugas, maka setiap sensor akan mengirimkan nilai atau data ke database dan ditampilkan pada halaman website. Speaker akan aktif untuk membunyikan suara burung setiap 1 jam sekali, serta untuk keamanan kandang menggunakan sensor finger print dan solenoid door lock untuk membuka pintu sangkar burung. Proses kerja pada alat ini di tunjukkan pada Gambar 17

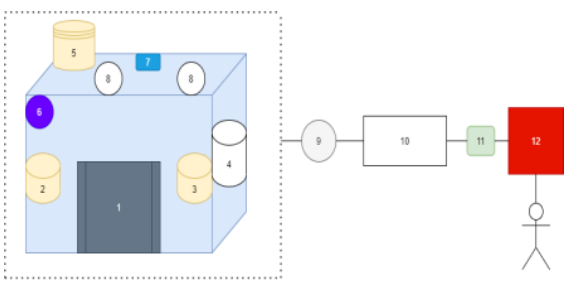

Gambar 17 Blok diagram sistem 


\subsection{Flowchart Sistem}

Flowchart sistem ini menjelaskan proses berjalananya alat seperti ditunjukkan pada Gambar 18.

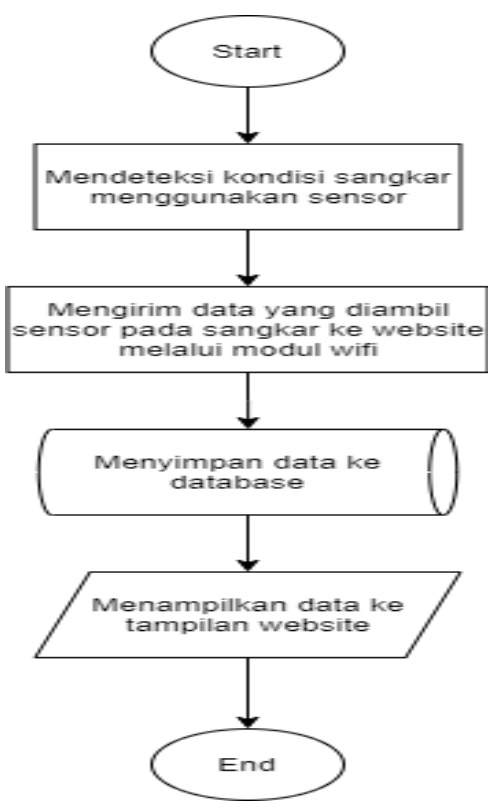

Gambar 18 Flowchart Sistem

Pada flowchart di atas sistem dimulai dengan sensor yang terdapat pada sangkar burung akan mendeteksi kondisi dari sangkar dan mengambil data dari kondisi lalu mengirimkan data ke database dengan perantara modul esp. data yang telah diterima oleh database maka selanjutnya akan ditampilkan pada halaman website untuk memonitoring sangkar burung.

\subsection{Flowchart Alat}

Flowchart alat ini menjelaskan proses berjalananya alat seperti ditunjukkan pada Gambar 19.

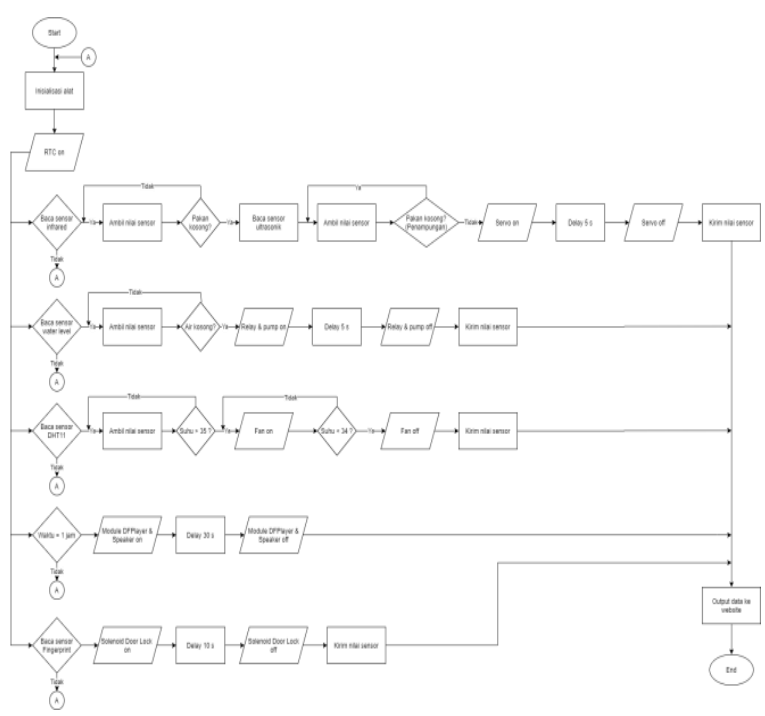

Gambar 19 Flowchart Alat
Pada flowchart di atas sistem dimulai dengan inisialisasi alat saat alat sudah terkoneksi maka RTC akan aktif untuk membaca waktu pemberian pakan dan waktu menyalakan speaker. Saat waktu telah terkomfirmasi maka infrared akan membaca data apakah pakan pada wadah pakan burung kosong atau tidak, jika pakan ada makan sensor ultrasonik akan mendeteksi apakah pakan pada penampungan ada, jika ada makan motor servo akan aktif dan membuka penutup saluran pakan selama 5 detik setelah 5 detik makan penutup pakan akan tertutup dan motor servo non-aktif. Sensor water level akan mendeteksi apakah air pada wadah minum burung kosong atau tidak, jika kosong maka relay akan menyalurkan daya listrik kepompa atau pump untuk menyalurkan air ke wadah air minum selama 5 detik. Sensor dht 11 akan membaca suhu kandang apakah bersuhu 35 celcius atau tidak, jika suhu di atas $35 \mathrm{C}$ maka fan akan aktif untuk membuat kandang menjadi dingin. Fan akan aktif selama suhu bernilai diatas $35 \mathrm{C}$ dan akan non-aktif bila suhu berada dibawah $34 \mathrm{C}$. Module DFPlayer mini dan speaker akan aktif setiap 1 jam sekali untuk melatih suara burung dan delay selama 30 detik. Sensor finger print akan mendeteksi sidik jari apakah terdaftar ataukan tidak, jika sidik jari terdaftar maka solenoid door lock akan aktif dan pintu sangkar dapat dibuka. Untuk setiap data sensor akan langsung di kirim ke database memalui esp8266 dan akan tampil pada halaman website.

\subsection{Protipe Disain Alat}

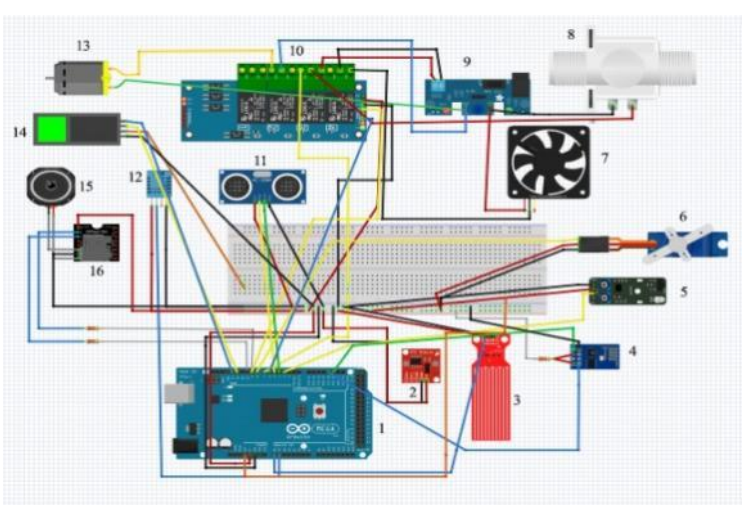

Gambar 20 Desain Alat

\section{HASIL DAN PEMBAHASAN}

Pada bab ini akan ditunjukkan hasil dan pembahasan terhadap proses yang telah dilakukan.

\subsection{Pengujian Sensor Sidik Jari AS608}

Pengujian menggunakan sensor sidik jari dengan tipe AS608 ini berfungsi untuk mengetahui kemampuan sensor dan dalam memindai sidik jari, sebelum membandingkan gambar yang baru saja diambil dengan data yang telah disimpan di chip DSP (Digital Signal Processor) yang terletak dalam modul. Dapat dilihat pada tabel 2. 
Tabel 2 Pengujian Sensor Sidik Jari AS608

\begin{tabular}{|l|l|l|l|l|l|l|l|l|l|}
\hline No & Pendeteksi & Id & \multicolumn{2}{|c|}{ Waktu Pendeteksian } & $\begin{array}{l}\text { Rata-rata } \\
\text { deteksi }\end{array}$ & Status & $\begin{array}{l}\text { Solenoid } \\
\text { door lock }\end{array}$ \\
\hline 1 & $\begin{array}{l}\text { Jari Jempol (Orang } \\
\text { Pertama) }\end{array}$ & 1 & $1.27 \mathrm{~s}$ & $1.29 \mathrm{~s}$ & $1.28 \mathrm{~s}$ & $1.28 \mathrm{~s}$ & $\begin{array}{l}\text { Image } \\
\text { taken dan } \\
\text { rekam data }\end{array}$ & Aktif \\
\hline 2 & $\begin{array}{l}\text { Jari Jempol (Orang } \\
\text { Kedua) }\end{array}$ & 2 & $1.22 \mathrm{~s}$ & $1.07 \mathrm{~s}$ & $1.17 \mathrm{~s}$ & $1.15 \mathrm{~s}$ & $\begin{array}{l}\text { Image } \\
\text { taken dan } \\
\text { rekam data }\end{array}$ & Aktif \\
\hline 3 & $\begin{array}{l}\text { Jari Jempol (Orang } \\
\text { Ketiga) }\end{array}$ & 3 & $1.12 \mathrm{~s}$ & $1.12 \mathrm{~s}$ & $1.36 \mathrm{~s}$ & $1.2 \mathrm{~s}$ & $\begin{array}{l}\text { Image } \\
\text { taken dan } \\
\text { rekam data }\end{array}$ & Aktif \\
\hline 4 & $\begin{array}{l}\text { Jari Telunjuk (Orang } \\
\text { pertama) }\end{array}$ & 4 & $1.31 \mathrm{~s}$ & $1.36 \mathrm{~s}$ & $1.26 \mathrm{~s}$ & $1.31 \mathrm{~s}$ & $\begin{array}{l}\text { Image dan } \\
\text { taken dan } \\
\text { rekam data }\end{array}$ & Aktif \\
\hline 5 & $\begin{array}{l}\text { Jari Telunjuk (Orang } \\
\text { kedua) }\end{array}$ & 5 & $1.21 \mathrm{~s}$ & $1.16 \mathrm{~s}$ & $1.15 \mathrm{~s}$ & $1.17 \mathrm{~s}$ & $\begin{array}{l}\text { Image } \\
\text { taken dan } \\
\text { rekam data }\end{array}$ & Aktif \\
\hline 6 & $\begin{array}{l}\text { Jari Telunjuk (Orang } \\
\text { Ketiga) }\end{array}$ & 6 & $1.09 \mathrm{~s}$ & $1.24 \mathrm{~s}$ & $1.06 \mathrm{~s}$ & $1.13 \mathrm{~s}$ & $\begin{array}{l}\text { Image } \\
\text { taken dan } \\
\text { rekam data }\end{array}$ & Aktif \\
\hline
\end{tabular}

Dari hasil pengujian sensor sidik jari ini terdapat 6 data sidik jari yang terdaftar pada sensor, waktu pembacaan data sidik jari berbeda-beda dan jika jari yang ditempelkan pada sensor basah atau berkeringat maka waktu pembacaan semakin lama.

\subsection{Pengujian Sensor Infrared IR}

Pengujian menggunakan sensor infrared berfungsi untuk mengetahui tingkat keakuratan dalam pembacaan jarak yang dapat dideteksi oleh sensor infrared dengan memutar potensio dari sensor. Dapat dilihat pada tabel 3 .

Tabel 3 Pengujian Sensor Infrared IR

\begin{tabular}{|l|c|l|}
\hline Putaran trimot Potensio Meter & $\begin{array}{c}\text { Jarak Maksimal Objek } \\
\text { Terdeteksi }\end{array}$ & \multicolumn{1}{|c|}{ Keterangan } \\
\hline $\begin{array}{l}0 \% \text { (Penuh berlawanan arah } \\
\text { jarum jam) }\end{array}$ & - & $\begin{array}{l}\text { Status sensor HIGH (Tidak } \\
\text { mendeteksi objek pada semua jarak) }\end{array}$ \\
\hline $10 \%$ & $1 \mathrm{~cm}$ & $\begin{array}{l}\text { Sensor dapat mendeteksi objek } \\
\text { sampai dengan } 1 \mathrm{~cm}\end{array}$ \\
\hline $20 \%$ & $9 \mathrm{~cm}$ & $\begin{array}{l}\text { Sensor dapat mendeteksi objek } \\
\text { sampai dengan } 4 \mathrm{~cm}\end{array}$ \\
\hline $50 \%$ & $13 \mathrm{~cm}$ & $\begin{array}{l}\text { Sensor dapat mendeteksi objek } \\
\text { sampai dengan } 9 \mathrm{~cm}\end{array}$ \\
\hline $60 \%$ & $20 \mathrm{~cm}$ & $\begin{array}{l}\text { Sensor dapat mendeteksi objek } \\
\text { sampai dengan } 13 \mathrm{~cm}\end{array}$ \\
\hline $80 \%$ & $\begin{array}{l}\text { Sensor dapat mendeteksi objek } \\
\text { sampai dengan } 20 \mathrm{~cm}\end{array}$ \\
\hline $100 \%$ (Penuh, searah jarum & $\begin{array}{l}\text { Status Sensor LOW (Mendeteksi } \\
\text { objek). Walaupun tidak ada objek }\end{array}$ \\
\hline jam)
\end{tabular}

Dari hasil pengujian terdapat 7 data yang dimana pada saat pengujian potensio yang ada di sensor infrared diputar dan diberi halangan hanya dapat mendeteksi jarak maksimum $20 \mathrm{~cm}$ dengan putaran potensio $80 \%$ searah jarum jam.

\subsection{Pengujian Sensor Ultrasonik HC-SR04}

Pengujian menggunakan sensor ultrasonik berfungsi untuk mengetahui tingkat keakuratan dalam pembacaan jarak yang dapat dideteksi oleh sensor ultrasonik. Dapat dilihat pada tabel 4.
Tabel 4 Pengujian Sensor Ultrasonik HC-SR04

\begin{tabular}{|c|c|c|c|}
\hline No & Data Penggaris & Data Sensor (Jarak) & Presentase Error \\
\hline 1 & $5 \mathrm{~cm}$ & $5.13 \mathrm{~cm}$ & $2,5 \%$ \\
\hline 2 & $10 \mathrm{~cm}$ & $10.5 \mathrm{~cm}$ & $4,7 \%$ \\
\hline 3 & $15 \mathrm{~cm}$ & $15.16 \mathrm{~cm}$ & $1,05 \%$ \\
\hline 4 & $20 \mathrm{~cm}$ & $19.58 \mathrm{~cm}$ & $2,14 \%$ \\
\hline 5 & $25 \mathrm{~cm}$ & $24.28 \mathrm{~cm}$ & $3,68 \%$ \\
\hline 6 & $30 \mathrm{~cm}$ & $29.12 \mathrm{~cm}$ & $3,02 \%$ \\
\hline 7 & $35 \mathrm{~cm}$ & $34.42 \mathrm{~cm}$ & $1,63 \%$ \\
\hline 8 & $40 \mathrm{~cm}$ & $38.87 \mathrm{~cm}$ & $2,9 \%$ \\
\hline 9 & $45 \mathrm{~cm}$ & $44.63 \mathrm{~cm}$ & $0,8 \%$ \\
\hline 10 & $50 \mathrm{~cm}$ & $49.14 \mathrm{~cm}$ & $1,75 \%$ \\
\hline 11 & $55 \mathrm{~cm}$ & $54.03 \mathrm{~cm}$ & $1,79 \%$ \\
\hline 12 & $60 \mathrm{~cm}$ & $59.90 \mathrm{~cm}$ & $0,16 \%$ \\
\hline 13 & $65 \mathrm{~cm}$ & $63.94 \mathrm{~cm}$ & $1,65 \%$ \\
\hline 14 & $70 \mathrm{~cm}$ & $68.09 \mathrm{~cm}$ & $2,8 \%$ \\
\hline 15 & $75 \mathrm{~cm}$ & $74.18 \mathrm{~cm}$ & $1,1 \%$ \\
\hline 16 & $80 \mathrm{~cm}$ & $78.17 \mathrm{~cm}$ & $2,3 \%$ \\
\hline 17 & $85 \mathrm{~cm}$ & $83.73 \mathrm{~cm}$ & $1,5 \%$ \\
\hline 18 & $90 \mathrm{~cm}$ & $87.95 \mathrm{~cm}$ & $2,33 \%$ \\
\hline 19 & $95 \mathrm{~cm}$ & $93.15 \mathrm{~cm}$ & $1,9 \%$ \\
\hline 20 & $100 \mathrm{~cm}$ & $96.38 \mathrm{~cm}$ & $3,7 \%$ \\
\hline \multicolumn{3}{|c|}{ Rata - rata Error } & $2,17 \%$ \\
\hline
\end{tabular}

\subsection{Pengujian Sensor Water Level}

Pengujian menggunakan sensor water level berfungsi untuk mengetahui tingkat ketinggian air didalam wadah. Nilai yang dihasilkan dari pembacaan sensor water level ini adalah berupa keterangan value dan ketinggian air. Dapat dilihat pada tabel 5.

Tabel 5 Pengujian Sensor Water Level

\begin{tabular}{|l|c|c|c|c|c|}
\hline \multirow{2}{*}{ No } & \multirow{2}{*}{ Voltage (V) } & \multicolumn{2}{|c|}{ Sensor } & \multirow{2}{*}{ Mistar } & Error \\
\cline { 3 - 4 } & & Value & Tinggi Air & & \\
\hline 1 & 2.31 & 473 & $1.75 \mathrm{~cm}$ & $1.6 \mathrm{~cm}$ & $8,6 \%$ \\
\hline 2 & 2.64 & 540 & $2.15 \mathrm{~cm}$ & $2 \mathrm{~cm}$ & $7 \%$ \\
\hline 3 & 2.85 & 583 & $2.28 \mathrm{~cm}$ & $2.2 \mathrm{~cm}$ & $3.5 \%$ \\
\hline 4 & 2.02 & 414 & $1.52 \mathrm{~cm}$ & $1.4 \mathrm{~cm}$ & $7.8 \%$ \\
\hline 5 & 2.78 & 486 & $1.92 \mathrm{~cm}$ & $1.8 \mathrm{~cm}$ & $6.25 \%$ \\
\hline 6 & 2.67 & 538 & $2.58 \mathrm{~cm}$ & $2.4 \mathrm{~cm}$ & $6.9 \%$ \\
\hline 7 & 2.53 & 523 & $2.41 \mathrm{~cm}$ & $2.3 \mathrm{~cm}$ & $4.56 \%$ \\
\hline 8 & 2.79 & 553 & $2.74 \mathrm{~cm}$ & $2.6 \mathrm{~cm}$ & $5.1 \%$ \\
\hline 9 & 2.94 & 610 & $2.96 \mathrm{~cm}$ & $2.8 \mathrm{~cm}$ & $5.4 \%$ \\
\hline 10 & 1.03 & 312 & $1.05 \mathrm{~cm}$ & $1 \mathrm{~cm}$ & $4.76 \%$ \\
\hline 11 & 2.38 & 457 & $1.59 \mathrm{~cm}$ & $1.5 \mathrm{~cm}$ & $5.66 \%$ \\
\hline 12 & 2.35 & 523 & $2.10 \mathrm{~cm}$ & $1.9 \mathrm{~cm}$ & $9.52 \%$ \\
\hline 13 & 2.96 & 732 & $3.17 \mathrm{~cm}$ & $3 \mathrm{~cm}$ & $5.36 \%$ \\
\hline 14 & 3.04 & 764 & $3.23 \mathrm{~cm}$ & $3.1 \mathrm{~cm}$ & $4 \%$ \\
\hline 15 & 3.25 & 798 & $3.49 \mathrm{~cm}$ & $3.3 \mathrm{~cm}$ & $5.44 \%$ \\
\hline \multicolumn{7}{|c|}{ Rata-rata Error } & $5.99 \%$ \\
\hline
\end{tabular}

\subsection{Pengujian Sensor DHT11}

Pengujian menggunakan sensor dht11 berfungsi untuk mengetahui kondisi suhu dari sangkar burung dan keakuratan pembacaan sensor dht11. Nilai yang dihasilkan dari pembacaan sensor dht11 ini adalah tingkat suhu dan kelembaban udara yang terdeteksi oleh sensor, untuk mengetahui keakuratan dari sensor dht11 dalam pengujian ini memerlukan alat bantu berupa thermometer ruangan. Dapat dilihat pada tabel 6. 
Tabel 6 Pengujian Sensor DHT11

\begin{tabular}{|l|c|c|c|}
\hline No & Sensor & Thermometer & Error \\
\hline 1 & $32 \mathrm{C}$ & $31 \mathrm{C}$ & $3.1 \%$ \\
\hline 2 & $33 \mathrm{C}$ & $31 \mathrm{C}$ & $6.06 \%$ \\
\hline 3 & $30 \mathrm{C}$ & $30 \mathrm{C}$ & $0 \%$ \\
\hline 4 & $31 \mathrm{C}$ & $30 \mathrm{C}$ & $3.22 \%$ \\
\hline 5 & $29 \mathrm{C}$ & $29 \mathrm{C}$ & $0 \%$ \\
\hline 6 & $33 \mathrm{C}$ & $32 \mathrm{C}$ & $3 \%$ \\
\hline 7 & $33 \mathrm{C}$ & $31 \mathrm{C}$ & $6.06 \%$ \\
\hline 8 & $31 \mathrm{C}$ & $31 \mathrm{C}$ & $0 \%$ \\
\hline 9 & $30 \mathrm{C}$ & $29 \mathrm{C}$ & $3.33 \%$ \\
\hline 10 & $30 \mathrm{C}$ & $30 \mathrm{C}$ & $0 \%$ \\
\hline 11 & $31 \mathrm{C}$ & $30 \mathrm{C}$ & $3.22 \%$ \\
\hline 12 & $31 \mathrm{C}$ & $32 \mathrm{C}$ & $3.22 \%$ \\
\hline 13 & $29 \mathrm{C}$ & $30 \mathrm{C}$ & $3.44 \%$ \\
\hline 14 & $32 \mathrm{C}$ & $33 \mathrm{C}$ & $3.1 \%$ \\
\hline 15 & $32 \mathrm{C}$ & $32 \mathrm{C}$ & $0 \%$ \\
\hline \multicolumn{4}{|l}{ Rata-rata error } \\
\hline
\end{tabular}

\subsection{Pengujian Modul ESP8266-01}

Pengujian menggunakan module esp8266-01 atau disebut juga modul wifi ini menggunakan pengujian pengiriman data dari sensor ke web server. Dapat dilihat pada tabel 7.

Tabel 7 Pengujian Modul ESP8266-01

\begin{tabular}{|l|c|c|c|}
\hline \multirow{2}{*}{ No } & \multicolumn{2}{|c|}{ Waktu } & \multirow{2}{*}{ Delay (detik) } \\
\cline { 2 - 3 } & Pengiriman & Tampilan Pada Website & \\
\hline 1. & $17-33-53$ & $17-34-03$ & 10 \\
\hline 2. & $17-34-09$ & $17-34-19$ & 10 \\
\hline 3. & $17-34-22$ & $17-34-32$ & 10 \\
\hline 4. & $17-34-37$ & $17-34-47$ & 10 \\
\hline 5. & $17-34-55$ & $17-35-05$ & 10 \\
\hline
\end{tabular}

Hasil dari pengujian modul wifi dapat diamati bahwa delay pada pengiriman data sudah sesuai yaitu 10 detik. Delay dibuat 10 detik untuk menjaga komponen agar tetap bekerja dengan optimal dan menghidari overheat pada komponen.

\subsection{Pengujian Monitoring Sangakar Burung}

Pengujian komponen dari alat sangkar burung ini terdiri dari minimum sistem Arduino Mega 2560, Sensor Fingerprint, Sensor Infared IR, Sensor Ultrasonik, Sensor Water Level, Sensor DHT11, Modul ESP8266-01, Modul DFPlayer Mini, RTC, Fan, Water Pump Mini, Motor Servo, Solenoid Door Lock, Power Supply dan Relay. Implementasi komponen yang terhubung pada minimum sistem arduino mega diletakkan pada sebuah box yang nantinya ditempatkan diatas sangkar.

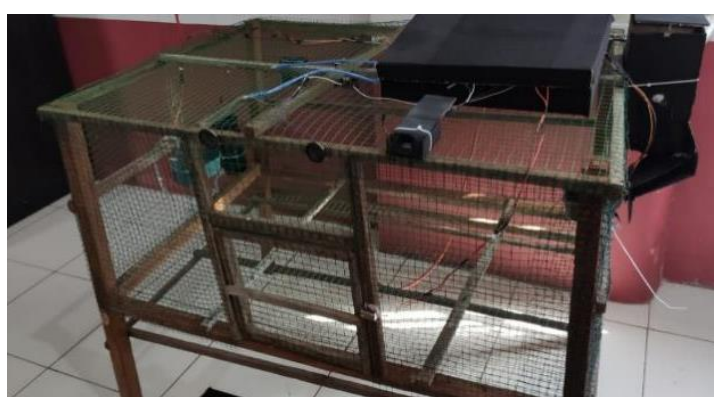

Gambar 21 Hasil Implementasi Komponen
Tabel 8 Pengujian Sangkar Burung

\begin{tabular}{|c|l|c|l|c|}
\hline No & \multicolumn{1}{|c|}{ Pengujian Alat } & RTC & \multicolumn{1}{|c|}{ Keterangan } & Hasil \\
\hline 1. & $\begin{array}{l}\text { Wadah Pakan \& } \\
\text { Penampungan } \\
\text { Pakan }\end{array}$ & On & $\begin{array}{l}\text { Alat aktif dan } \\
\text { mengirim data }\end{array}$ & $\sqrt{ }$ \\
\hline 2. & $\begin{array}{l}\text { Wadah minum } \\
\text { dan penampungan } \\
\text { air }\end{array}$ & On & $\begin{array}{l}\text { Alat aktif dan } \\
\text { mengirim data }\end{array}$ & $\sqrt{ }$ \\
\hline 3. & $\begin{array}{l}\text { Pengukur suhu } \\
\text { dan kipas angin }\end{array}$ & On & $\begin{array}{l}\text { Alat aktif dan } \\
\text { mengirim data }\end{array}$ & $\sqrt{ }$ \\
\hline 4. & $\begin{array}{l}\text { Deteksi sidik jari } \\
\text { dan pengunci } \\
\text { pintu }\end{array}$ & - & $\begin{array}{l}\text { Id terdeteksi, } \\
\text { pengunci pintu } \\
\text { terbuka dan } \\
\text { mengirim data }\end{array}$ & $\sqrt{ }$ \\
\hline 5. & Speaker & On & $\begin{array}{l}\text { Speaker aktif } \\
\text { selama durasi } \\
\text { musik }\end{array}$ & $\sqrt{ }$ \\
\hline
\end{tabular}

4.8. Tampilan Halaman Data Pakan dan Minum Tampilan halaman home dapat dilihat pada gambar 22.

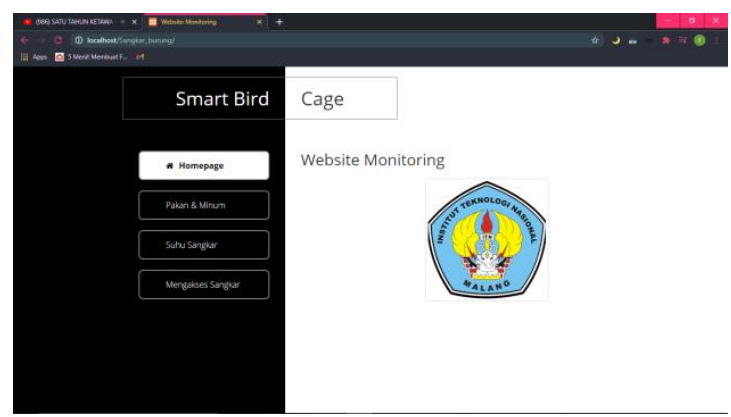

Gambar 22 Halaman Home

\subsection{Tampilan Halaman Data Pakan dan Minum}

Pada halaman data pakan dan minum menampilkan data kondisi wadah pakan, penampungan pakan dan wadah minum yang diambil dari sensor infrared, ultrasonic dan water level sebagai pembaca data dan ditampilkan dalam bentuk table dari data yang didapat. Dapat dilihat pada gambar 23.

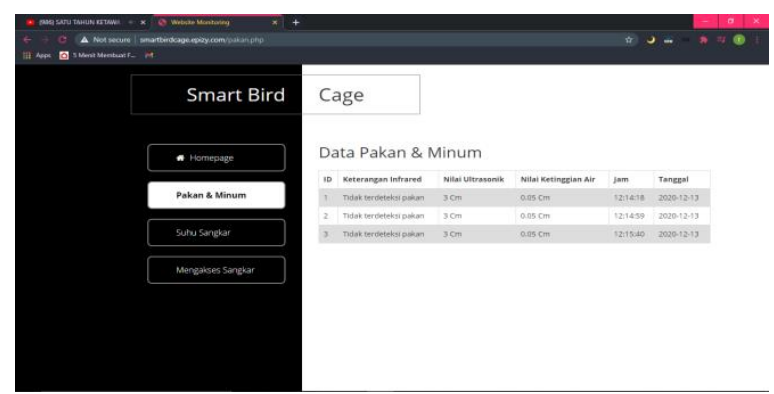

Gambar 23 Halaman Data Pakan dan Minum

\subsection{Tampilan Halaman Data Suhu}

Pada halaman data suhu menampilkan data kondisi suhu sangkar yang diambil dari sensor dht11 sebagai pembaca data dan ditampilkan pada halaman website, data suhu akan terupdate setiap 30 menit. Dapat dilihat pada gambar 24 


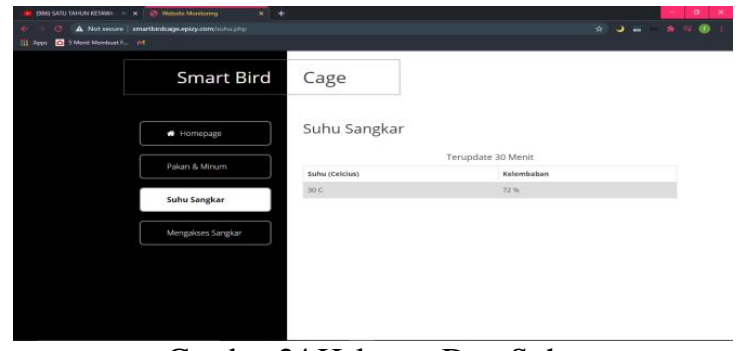

Gambar 24 Halaman Data Suhu

\subsection{Tampilan Halaman Data Sidik Jari}

Pada halaman data sidik jari menampilkan data setiap orang yang mengakses sangkar burung yang diambil dari sensor fingerprint. Data yang masuk ke website bersifat real time jika sensor mendeteksi adanya data yang masuk. Dapat dilihat pada gambar 25 .

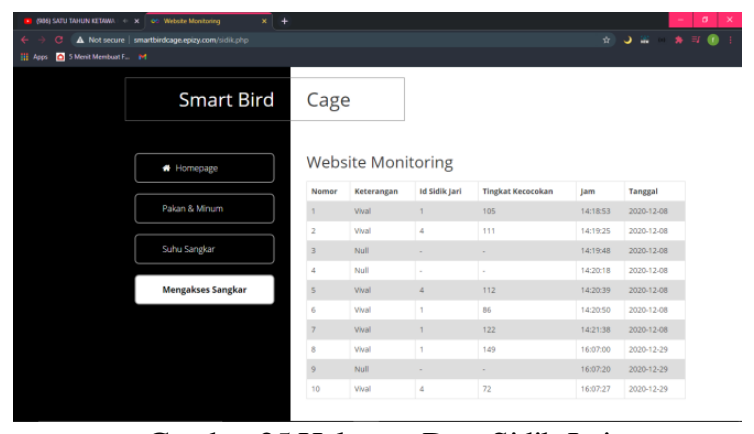

Gambar 25 Halaman Data Sidik Jari

\subsection{Pengujian Software}

Pengujian software pada penelitian ini dengan menguji kompabilitas website terhadap web browser. Hasil uji coba dari kompabilitas website terhadap web browser seperti ditunjukan pada Tabel 9.

Tabel 9 Pengujian Software

\begin{tabular}{|l|l|c|c|c|}
\hline \multirow{2}{*}{ No } & \multicolumn{1}{|c|}{$\begin{array}{c}\text { Aspek } \\
\text { Pengujian }\end{array}$} & $\begin{array}{c}\text { Mozila } \\
(48.0)\end{array}$ & $\begin{array}{c}\text { Chrome } \\
(86.0)\end{array}$ & $\begin{array}{c}\text { Microsoft } \\
\text { Edge (87.0) }\end{array}$ \\
\hline 1. & $\begin{array}{l}\text { Button } \\
\text { Menu }\end{array}$ & $\sqrt{ }$ & $\sqrt{ }$ & $\sqrt{ }$ \\
\hline 2. & $\begin{array}{l}\text { Tampilan } \\
\text { data sensor }\end{array}$ & $\sqrt{ }$ & $\sqrt{ }$ & $\sqrt{ }$ \\
\hline 3. & $\begin{array}{l}\text { Real time } \\
\text { data yang } \\
\text { masuk }\end{array}$ & $\sqrt{ }$ & $\sqrt{ }$ & $\sqrt{ }$ \\
\hline
\end{tabular}

\section{KESIMPULAN DAN SARAN}

\subsection{Kesimpulan} bahwa:

Dari percobaan penelitian ini dapat disimpulkan

1. Sistem sangkar burung yang dibuat dapat bekerja dengan baik untuk setiap alat yang digunakan dan dapat memonitoring pakan dan minum burung, suhu sangkar, serta kemanan sangkar.

2. Dari hasil pengujian sensor diketahui memiliki ratarata presentase error pada sensor ultrasonic sebesar $2.17 \%$, sensor water level sebesar $5.99 \%$, serta sensor dht11 2.51\%

3. Komunikasi sistem menggunakan modul wifi ESP8266-01 untuk mengirim data pada web server dari jarak jauh, menggunakan konsep IoT.
4. Dari hasil pengujian system alat sangkar burung teriep, mulai dari alat pemberian pakan dan minum serta monitoring suhu, keamanan sangkar dan alat pemancing suara burung dapat bekerja dengan baik.

\subsection{Saran}

Sistem rancang bangun sangkar burung yang di implementasikan di sangkar burung ini masih memiliki kekurangan, sehingga bisa dikembangkan agar menjadi lebih sempurna. Adapun beberapa saran yang dapat dikembangkan.

1. Membuat website yang dapat mengkontroling sangkar burung untuk mengatur waktu dan menambahkan file $\mathrm{mp} 3 \mathrm{ke}$ dfplayer mini.

2. Menambahkan platfrom android dalam bentuk aplikasi sehingga mampu di monitoring oleh pengguna lain.

\section{DAFTAR PUSTAKA}

[1] S. A. Sahrian, S. Yuliananda, "Rancang Bangun Alat Pemberi Pakan-Minum Burung Cinta (Lovebird) Berbasis Mikrokontroler Atmega16," Jurnal Volume 1, Nomor 1, Agustus 2018

[2] P. P. Bagas, "Rancang Bangun Kandang Ternak Burung Otomatis Berbasis Arduino", JATI (Jurnal Mahasiswa Teknik Informatika) Vol. 2 No. 2, September 2018

[3] Arief Rahman Wibowo, "Rancang Bangun Sangkar Burung Pintar Berbasis Arduino Uno," Jurnal Ilmiah Pengembangan IoT, Juli 2019

[4] H. O. Andry, D. I. Joseph, A. W Suryo, "Implementasi Sensor Piezoelectric Sebagai Midi Drum Controller Berbasis Arduino Uno" JATI (Jurnal Mahasiswa Teknik Informatika) Vol. 4 No. 1, Maret 2020

[5] Dimas Adi Pratama, S. A. (2018). PENGAIRAN DAN PEMBERIAN PAKAN OTOMATIS PADA AKUARIUM BERBASIS ARDUINO.

[6] Irawan, J.D., Prasetio, S. and Wibowo, S.A., 2016. IP based module for building automation system. In Proceedings of second international conference on electrical systems, technology and information 2015 (ICESTI 2015) (pp. 337- 343). Springer, Singapore.

[7] Widiyamana, T. (2020, Agustus 11). WARRIORNUX. (GeneratePress) Dipetik September 01, 2020, dari https://www.warriornux.com/pengertian-modulwifi-esp8266/

[8] Faturahman, Jeni, 2013. Aplikasi Monitoring Keamanan Ruangan Berbasis Mikrokontroler Arduino Mega Pada Toko Mas Diamond, Jakarta: Universitas Budi Luhur.

[9] DFPlayer - A Mini MP3 Player [internet]. 2014. Available form: https://www.dfrobot.com/wiki/ index.php/DFPlayer_Mini_SKU: DFR0299

[10] Djuric, Stanka. (2017). Economy "smart buildings" housing. (JPMNT) Journal of Process Management-New Technologies, International. 